\title{
Equidade na Educação Superior no Brasil: Uma Análise Multinomial das Políticas Públicas de Acesso*
}

\author{
Cristina B. de Souza Rossetto ${ }^{1}$ \\ Flávio de Oliveira Gonçalves ${ }^{1}$ \\ ${ }^{1}$ Universidade Federal do Paraná (UFPR), Curitiba, PR, Brasil. \\ E-mail de contato: csouza.economia@gmail.com
}

\section{INTRODUÇÃO}

$\mathrm{O}$

estudante típico do ensino superior no Brasil é mulher, branca, estuda em uma instituição de ensino superior (IES) privada, no período noturno, em curso de bacharelado de Ciências Sociais Aplicadas; tem renda familiar de até 10 salários mínimos, trabalha e não recebe qualquer benefício público para financiar sua educação (Inep, 2014a; Inep, 2014b).

A educação superior, ao longo de sua história, teve predominância das IES privadas (Moehlecke, 2004). Enquanto gratuitas, IES públicas têm vantagens competitivas na atração dos alunos. Assim, ao longo da história, observou-se a constituição de uma elite de maior renda e com resultados de qualidade de educação percebidos como superiores na rede pública (Cunha, 2004). Essa elitização refletia processos de desigualdade socioeconômica presentes também em outras esferas da sociedade, inclusive na formação educacional precedente ao ensino superior.

Ao fim dos anos 1990 o ensino público começou a sofrer influência das políticas de ação afirmativa. Em 2012 essa política teve forte expansão,

\footnotetext{
* O estudo foi desenvolvido no âmbito do Núcleo de Avaliação de Políticas Públicas Educacionais (Nappe), da Universidade Federal do Paraná (UFPR) e os autores agradecem à Coordenação de Aperfeiçoamento de Pessoal de Nível Superior (Capes) e ao Conselho Nacional de Desenvolvimento Científico e Tecnológico (CNPq) pelo apoio financeiro à pesquisa.
}

DADOS - Revista de Ciências Sociais, Rio de Janeiro, vol. 58, n-3, 2015, pp. 791 a 824. 
dada a lei que define que $50 \%$ das vagas das IES federais devem ser destinadas a alunos cotistas (Presidência, 2012). Porém, o sistema público abrange não mais que $25 \%$ da oferta de vagas. Para discutir a equidade de acesso ao ensino superior no Brasil é essencial considerar os mecanismos de acesso de forma integrada, considerando tanto políticas para IES públicas como privadas.

O objetivo deste artigo é analisar o acesso ao ensino superior no Brasil a partir de critérios de justiça distributiva, mais especificamente, da abordagem de igualdade de oportunidades. Contribuições particulares deste trabalho estão justamente no embasamento da abordagem de igualdade de oportunidades e no enfoque integrado. Não se trata de fazer uma avaliação aprofundada de cada uma das políticas em suas diversas implicações e problemáticas, a saber, o Programa Universidade para Todos (ProUni), o Fundo de Financiamento Estudantil (FIES) e as cotas, mas de observar se elas seguem critérios coerentes entre si e aderem aos princípios de igualdade de oportunidades como um todo. Essas políticas têm em comum o fato de destinarem-se a grupos específicos da sociedade. Diversos trabalhos avaliam tais políticas isoladamente: Baroni (2010), Pereira (2013) e Duenhas (2013) para públicas; Saraiva e Nunes (2011), Andrade (2007), Aprile e Barone (2009) e Gemaque e Chaves (2010) para privadas. Finalmente, a avaliação empírica por modelos econométricos agrega elementos importantes, que subsidiam e corroboram as posições defendidas neste trabalho.

Teorias de justiça distributiva discutem "como a sociedade ou um grupo deve alocar seus recursos ou produtos escassos entre os indivíduos, os quais têm necessidades e demandas concorrentes entre si" (Roemer, 1996:1; tradução livre). É um contexto mais amplo no qual se inserem as questões relacionadas à igualdade de oportunidades. Diversas teorias de justiça distributiva propõem soluções distintas para o problema da equidade, mas, para analisar casos concretos, é necessário optar e se aprofundar em uma delas. Esta escolha não significa que as demais teorias sejam menos relevantes. A escolha de princípios norteadores da política é um exercício normativo, que deve ser expressão dos valores de uma determinada sociedade. O pesquisador contribui para o debate público oferecendo interpretações desses princípios teóricos para a aplicação prática.

O conceito de igualdade de oportunidades sugere que características não controláveis pelos indivíduos, como sua procedência familiar, sua 
carga genética etc. não sejam determinantes para definir posições na sociedade. Deveriam contar apenas variáveis que os indivíduos controlam, como esforço, preferências etc. Assim, as políticas públicas têm o papel de compensar os indivíduos por suas desvantagens relacionadas às características não controláveis (Cohen, 1989; Bénabou, 2000; Roemer, 2000, 2012).

Buscaram-se evidências empíricas sobre características das desigualdades. Utilizou-se um modelo logit multinomial para identificar como variáveis de condição (renda, cor, escolaridade dos pais etc.) e esforço (horas de estudo, trabalho, atividades acadêmicas) influenciam a probabilidade de os alunos receberem os incentivos providos pelas políticas de cotas, FIES e o ProUni. Utilizaram-se os microdados do Exame Nacional de Desempenho de Estudantes (Enade) para ingressantes entre 2008 e 2010.

As estimativas têm um limite por serem realizadas a partir de amostra censurada dos alunos demandantes de ensino superior, pois não estão disponíveis dados representativos dos processos seletivos para estes anos. Além disso, há viés de seleção amostral, uma vez que não há informações sobre indivíduos que gostariam de acessar o ensino superior e nem tentaram ou daqueles que poderiam acessar, mas não tiveram interesse. Assim, espera-se que haja subestimação das disparidades de oportunidade, pois é possível observar apenas aqueles que efetivamente acessaram o ensino superior.

Os resultados econométricos refletem o arcabouço institucional e socioeconômico do período analisado, isto é, 2008 a 2010. Assim, apontam incoerências no direcionamento das políticas de equidade de acesso ao ensino superior do período. Por exemplo, alunos das IES públicas sem cotas apresentaram condições socioeconômicas superiores às de quase todos os demais grupos avaliados e recebem educação gratuita, enquanto alunos em condições piores, como os do ProUni, não têm educação gratuita na média (quando consideradas bolsas parciais). Outro resultado é que a política de cotas no período privilegia mais o critério de cor que o de renda, quando comparado com o ProUni. Esse resultado poderá ser influenciado pela nova lei de cotas, que dá prioridade ao critério "Ensino Médio público", seguido de renda e raça.

Ainda sobre os resultados, uma característica relevante de todas as categorias é o trabalho. Seria importante determinar quão essencial o trabalho é para a permanência no ensino superior, mas a base de dados 
não permite realizar tais assertivas. Seria possível observar, por exemplo, se alunos de renda média das privadas sem qualquer benefício teriam desvantagem econômica frente aos alunos das públicas sem cotas e as compensam com o trabalho.

Os resultados empíricos apontam que as políticas segmentadas para instituições públicas e privadas, como estabelecidas no período analisado, são inadequadas para produzir incentivos equânimes à entrada no ensino superior. De modo geral, questiona-se o fato de as políticas apresentarem critérios distintos para focalização dos subsídios. A política de cotas encontra legitimidade sob o conceito de igualdade de oportunidades, mas é a que mais restrições impõe aos alunos e restringe-se ao ensino público. O FIES, apesar de estar disponível para boa parte dos demandantes do ensino superior e seu recente aperfeiçoamento, permanece como opção de política de maior custo aos alunos. $\mathrm{O}$ ProUni tem como principal debilidade a incapacidade de expandir-se na mesma proporção que a demanda, pois está restrito às desonerações fiscais geradas com a concessão de bolsas.

O artigo está dividido em cinco seções, além desta Introdução. Primeiro apresenta-se a discussão sobre justiça distributiva de forma geral e o conceito de igualdade de oportunidades. Na sequência, busca-se uma interpretação aplicada destes conceitos para o contexto do ensino superior. A terceira traz uma descrição do sistema de ensino superior no Brasil e das políticas de equidade de acesso: cotas, FIES e ProUni. A seção seguinte contempla a análise econométrica e seus resultados. Por fim, discutem-se direcionamentos de política pública para ampliar a igualdade de oportunidades no acesso ao ensino superior no Brasil.

\section{TEORIAS DE JUSTIÇA DISTRIBUTIVA E O CONCEITO DE IGUALDADE DE OPORTUNIDADES}

Discussões sobre justiça são tão antigas quanto a filosofia. A cada época, as problemáticas são diferentes, ligadas aos desafios do próprio contexto histórico. Maffetone e Veca (2005) apontam o fim do século XVIII como o momento em que o interesse dos teóricos da justiça desloca-se da boa ordem política e do propósito das instituições para o âmbito das interações e das relações de conflito e cooperação social. Então, "a questão social (...) tem como êxito paradigmático a interpretação da justiça como justiça distributiva" (idem:227). Os autores apon- 
tam a teoria rawlsiana como um marco, a partir do qual houve um grande florescimento de teses sobre justiça distributiva.

O contexto em que este artigo se apresenta é pós-Rawls, cuja principal preocupação foi criar uma teoria de contraponto à teoria utilitarista. $\mathrm{O}$ ponto fundamental da teoria utilitarista para as questões de equidade é que o valor é atribuído pelos indivíduos de acordo com suas preferências e medido segundo sua utilidade. O bem deve ser alocado àquele que atribui maior utilidade marginal a ele, independente do grau de essencialidade do bem (Sen, 2009). Rawls preocupou-se em produzir uma teoria mais objetiva, que permitisse dar maior peso às necessidades básicas das pessoas, sobretudo as mais desprovidas da sociedade.

Na teoria rawlsiana o objetivo da sociedade é maximizar o bem-estar daqueles que estão nas piores condições, um critério conhecido por max-min (Rawls, 1971; Roemer, 2012). Rawls foi relativamente preciso ao indicar que tipo de elementos deveriam contar para o bem-estar e propõe que se pense em termos de bens sociais primários: liberdade, oportunidades, renda e riqueza, e as bases para o autorrespeito (Ralws, 1971).

Uma linha de pensamento próxima a de Rawls propõe o Commodity Egalitarianism, onde importa que todos tenham o suficiente para sobreviver de algumas determinadas commodities (Tobin, 1970). O importante não é a riqueza relativa, mas a absoluta. Existe um padrão mínimo de recursos que uma pessoa deve acessar para viver e, caso outros se tornem muito ricos, isto não seria um problema. Autores como Nozick e Sen enfatizam não somente recursos, mas o processo em que estes são adquiridos. Argumentam que neste processo as pessoas devam ter sua liberdade de escolha garantida (Sen, 2009).

Outra crítica importante à teoria rawlsiana de Sen (2009) diz respeito à factibilidade da sua proposta. O autor aponta que Rawls propõe um padrão ideal de justiça, que é forjado a partir de uma visão única (contratualista) da sociedade. Sen propõe que, ao invés de preestabelecer uma visão de justiça ideal, que prescinde de consensos na sociedade, que as situações concretas sejam avaliadas dentro daquilo que a realidade permite em termos de transformação, prevenindo injustiças severas evidentes.

O pragmatismo de Sen mostra-se pertinente frente ao objetivo de julgar política pública. Poder-se-ia defender que não adiantaria investir 
em equidade no ensino superior, se a desigualdade está presente em fases anteriores da vida do educando, como de fato evidenciam OECD (2008) e Dill e Gonçalves (2012). Para Sen, existe sempre a possibilidade de criar arranjos mais eficientes e eficazes.

Nos interessa perceber elementos comuns às diversas teorias, que permitam uma interpretação e aplicação ao problema mencionado. De maneira geral, as diferentes teorias de justiça distributiva oferecem diferentes respostas às questões "O que um indivíduo merece?" ou "A que um indivíduo tem direito?". Lados extremos seriam: cada um está sozinho na competição pela vida que almeja e, então, fatores genéticos e herança poderiam ser primordiais na distribuição dos recursos. Num outro extremo haveria uma igualdade absoluta: tudo dividido igualmente entre todos, independentemente de quaisquer características individuais. Obviamente estes são exemplos hipotéticos, e as teorias são muito mais profundas do que isso (Arrow, Bowles e Durlauf, 2000).

O conceito de igualdade de oportunidades é um dos temas recorrentes às diversas teorias de justiça. Normalmente, não sintetiza toda uma teoria, mas é uma parte importante dela. Segundo Mithaug (1996), a ideia de igualdade de oportunidades enfatiza a responsabilidade da sociedade em garantir que os recursos necessários à autodeterminação sejam igualmente distribuídos entre os indivíduos. Para o autor, estabelecer boas regras de liberdade não é suficiente para garantir um ambiente em que todos sejam capazes de maximizar suas experiências de autodeterminação, sobretudo, aqueles sujeitos a armadilhas de pobreza e marginalização. A falta de meios pode ser a causa da incapacidade de certos indivíduos em alcançar posições almejadas na sociedade e usufruir plenamente dos seus direitos de liberdade.

Teóricos desse tipo de igualitarismo buscam identificar e separar as circunstâncias que dependem apenas do comportamento dos indivíduos e aquelas que dependem de elementos fortuitos dependentes da sociedade e do contexto em que se encontram (Anderson, 1999). Existem dois tipos de características a serem consideradas na avaliação da igualdade de oportunidades, conforme Bénabou (2000): características herdadas pelos indivíduos sobre as quais eles não têm controle, e as que estão no controle dos indivíduos e que eles podem desenvolver. Por exemplo, no primeiro caso estão a carga genética e o padrão socioeconômico dos pais. No segundo, estão o esforço, as preferências e as decisões. Para fins práticos, a partir de agora, todas as 
características não controláveis serão chamadas "condições" e todas as controláveis serão "esforço".

Para Roemer (2000) há duas concepções prevalentes sobre igualdade de oportunidades, e uma não substitui a outra. A primeira significa "aplainar o terreno" para que os indivíduos possam competir, isto é, durante um período da formação dos indivíduos, as diferenças que gerem desvantagens de competição no futuro, por se relacionarem com condições não controláveis por eles (sexo, cor, nível socioeconômico dos pais, origem geográfica, entre outros), devem ser reduzidas. Assim, a partir de determinado momento, com igualdade de oportunidades estabelecidas, a sociedade não deve mais se preocupar em compensar as desigualdades e, então, os indivíduos passarão a competir por posições beneficiando-se apenas dos próprios esforços.

Num modelo simples, estes dois elementos são independentes entre si, mas obviamente existem situações em que isto não é verdade. Por exemplo, pais com grau de escolaridade maior podem ser mais exigentes quanto ao nível de esforço dos seus filhos. Por uma limitação metodológica, para o exercício econométrico será utilizada a versão simplificada do modelo, na qual não há interação.

A segunda concepção de igualdade de oportunidades é conhecida por nondiscrimination principle, e implica que indivíduos elegíveis para determinadas posições deveriam ser aqueles que possuem os atributos necessários para exercê-las. Por exemplo, para estar na posição de médico é necessário ter estudado medicina - este é o critério de inclusão nessa função, independentemente de suas condições. De outra forma, implica que diferenças existentes entre indivíduos, que são irrelevantes face ao cumprimento destas funções, não deveriam ser critério discriminatório, como por exemplo: sexo ou cor não deve ser critério para seleção de professores, mas a diplomação; parentesco não deve ser critério para que alguém assuma um cargo público, mas seu conhecimento sobre as funções do cargo (Roemer, 2000).

Seguindo Cohen na busca pela igualdade de oportunidades existe um espaço para a política pública, que é "compensar somente por aqueles déficits de bem-estar que não são de alguma maneira derivados das escolhas do indivíduo. Devemos substituir igualdade de bem-estar por igualdade de oportunidades por bem-estar" (1989:914; tradução livre). Apesar de claro no sentido, definir na prática quais sejam esses déficits é uma tarefa extremamente difícil. 
Uma dificuldade já mencionada é analisar características individuais resultantes da interação entre condição e esforço. Outra dificuldade diz respeito ao timing da política. Para Roemer (2000), em todas as visões do conceito existe o preceito de que em algum momento o indivíduo se torna o único responsável pelas suas conquistas ou fracassos, diante de suas necessidades ou aspirações. O que não é claro e passa a ser importante para a definição de políticas públicas é a definição deste ponto no tempo, que ele chama de "portão de partida": "As diferentes visões de igualdade de oportunidades podem ser categorizadas de acordo com onde se coloca o 'portão de partida', o qual marca o ponto onde cada indivíduo está por si só" (Roemer, 2000:18; tradução livre). Como veremos adiante, esta questão não é clara no Brasil para o caso dos investimentos públicos em educação.

Este artigo limita-se a discutir as políticas públicas de compensação. Outro foco seria a responsabilidade dos indivíduos sobre suas conquistas, conforme Fleurbaey (2008). O autor apresenta princípios de recompensa sensíveis às responsabilidades individuais. Neste estudo, adota-se a posição de que o mercado é o responsável por organizar as recompensas dos indivíduos, a partir do momento em que as políticas de compensação cessam.

\section{EDUCAÇÃO SUPERIOR E IGUALDADE DE OPORTUNIDADES}

A influência do pensamento rawlsiano e das teorias de justiça distributiva é cada vez mais evidente e orientadora das políticas públicas. Um documento da OECD (Organisation for Economic Co-operation and Development) de diretrizes para a educação expressa a equidade na educação de maneira fiel à linha teórica aqui apresentada:

A equidade em educação tem duas dimensões. A primeira é fairness, a qual implica que circunstâncias sociais e pessoais - por exemplo, gênero, status socioeconômico ou origem étnica - não devem ser um obstáculo para se alcançar o potencial educacional. A segunda é inclusão, que implica garantir um padrão educacional mínimo para todos (OECD, 2007:73; tradução livre).

Em outro documento, que trata especificamente do ensino superior, a OECD (2008) define que, além de preocupar-se com o acesso, pressupõe que políticas de equidade no ensino superior devem lidar com os efeitos de desigualdades educacionais passadas e promover oportunidades iguais no mercado de trabalho. Neste artigo propõe-se discutir 
apenas a equidade de acesso, o que exclui avaliar a qualidade da educação e como isso se reflete no mercado de trabalho.

Há argumentos contra estabelecer o mercado de trabalho como portão. Por exemplo, o fato de a escolaridade média de países desenvolvidos ser de 11,5 anos sugere ser possível alcançar altos níveis de produtividade ou bem-estar social sem que o ensino superior seja uma característica prevalente (UNDP, 2014). Além disso, o custo do ensino superior é alto e não é consenso que os ganhos sociais compensem o investimento público; se a maior parte do ganho for privado, ou seja, apropriado apenas pelos indivíduos, então também os investimentos em ensino superiordeveriam ser privados (Holsinger e Jacob, 2008; Barr, 2004).

O exercício proposto neste artigo sugere que o ensino superior não seja considerado obrigatório, tal como a educação básica, mas que o governo deva dar a todos que queiram a chance de acessá-lo.

Segundo Roemer (2000 e 2012), as oportunidades são avaliadas a partir de uma função de utilidade: $\mathrm{U}(C, e, \varphi)$, dado que " $C$ " representa as condições de cada indivíduo, " $e$ " é seu esforço e " $\varphi$ " é a política de intervenção do policy maker; "U" é a função que denota bem-estar no sentido econômico, que pode ser renda, expectativa de vida ou o potencial de ganho. A variável $\varphi$ deverá compensar o indivíduo por alguma condição em $C$ que lhe impeça melhorar $\mathrm{U}$, a despeito do seu nível de esforço.

Como mencionam Nunes (2011) e Holsinger e Jacob (2008), existem diversos elementos do processo de educação que podem compor $C$, ou seja, características que impedem que os indivíduos tenham condições de competição semelhantes. De forma objetiva, o policy maker tem diante de si ao menos duas questões: "Quais condições em $C$ são importantes para a política $\varphi$ ?" e "Qual é o público-alvo da política?".

Tentar conhecer todas as condições de cada indivíduo seria um exercício extremamente caro e provavelmente não se chegaria a uma resposta definitiva. Em geral, a literatura identifica certas categorias como importantes, como: escolaridade dos pais, nível socioeconômico (renda), migração, cor, sexo, proveniência (lugares longínquos) e presença de deficiências físicas ou cognitivas (OECD, 2007). No exercício econométrico realizado neste artigo apenas as variáveis migração e proveniência não foram consideradas, por falta de informação no primeiro 
caso e pela dificuldade de estabelecer o grau de isolamento dos mais de 5 mil municípios do país.

Para a definição do público-alvo, o desenho da política poderia optar por uma única variável de referência, como cor ou a renda domiciliar per capita ou criar um índice multidimensional, em que outras condições, como sexo e deficiência, informassem quais pessoas estão em piores condições. É ad doc o limite que separa "pobres" e "ricos".

\section{EDUCAÇÃO SUPERIOR NO BRASIL: ANÁLISE DESCRITIVA}

No sistema de ensino superior brasileiro convivem um setor público e outro privado. Nas IES públicas os alunos são completamente financiados pela sociedade, pois a educação é gratuita ${ }^{1}$. A ocupação por elites das vagas em IES públicas, conforme aponta Cunha (2004), na verdade reflete a formação de grupos de elite e as desigualdades socioeconômicas e educacionais como um todo. Desde a educação básica, grupos socioeconômicos diferentes ocupam espaços diferentes, recebendo investimentos e incentivos em proporções que mantêm ou acentuam diferenças de condições herdadas, impactando na qualidade da educação e na permanência dos alunos na escola (Andrade e Dachs, 2007; Gonçalves e França, 2008; Barreto, Codes e Duarte, 2012; Almeida, 2014). Nesse contexto, o ensino superior é a ponta da cadeia, onde provavelmente alguns prejuízos são irrecuperáveis (Heckman e Mosso, 2014).

No final dos anos 1990, universidades públicas começaram a implementar, de forma independente e autônoma, políticas de ação afirmativa (Moehlecke, 2004). Estas experiências geraram importante debate na sociedade, culminando em 2012 com aprovação de lei que define que $50 \%$ das vagas das IES federais sejam destinadas a alunos provenientes de escolas públicas, de baixa renda e minorias raciais (Presidência, 2012).

A rede privada, por sua vez, impõe aos alunos um outro tipo de barreira, a socioeconômica, pois existe pagamento de mensalidade. Ao fim dos anos 1990 o Estado criou o Programa de Financiamento Estudantil (FIES), atualmente Fundo de Financiamento Estudantil, e um programa de bolsas, o Universidade para Todos (ProUni) veio em seguida, com o objetivo de ampliar o acesso a este sistema. 
Em função do alcance do processo de discussão pública das leis de cotas, existe grande quantidade de artigos focando equidade de acesso para o alunado das IES públicas. Não existe discussão proporcional relativa às políticas voltadas às IES privadas ${ }^{2}$, quando esta rede absorve a maior parte da demanda por ensino superior no país. Em 2012 havia 7,06 milhões de matrículas ativas no ensino superior, sendo $73 \%$ na rede privada. Historicamente, sempre houve predominância do setor privado tanto em quantidade de instituições como de alunos (Inep, 2014a).

Em 2007 o governo federal lançou o Programa de Apoio a Planos de Reestruturação e Expansão das Universidades Federais (Reuni). O Reuni objetivava o aumento das vagas de ingresso e a redução das taxas de evasão nos cursos presenciais de graduação nas IES públicas federais (Brasil, 2007). De fato, o Reuni foi um marco para o ensino superior na rede pública, o qual gerou um acréscimo de $85 \%$ das vagas entre 2008 e 2012, quando no ensino privado o incremento foi de aproximadamente 60\% (Inep, 2014b).

Do ponto de vista de equidade ao acesso, o Reuni teve como principal virtude a ampliação das vagas no interior do país, onde a população é menos beneficiada pelos investimentos federais em ensino superior. No entanto, o Reuni diferencia-se das políticas de cotas, do FIES e do ProUni por não direcionar os benefícios a grupos específicos da sociedade, considerados em desvantagem. De fato, parece chamar mais atenção as mudanças que o Reuni gerou sobre a gestão universitária e sobre a expansão da rede federal de ensino (Araújo e Pinheiro, 2010; MEC, 2009) do que sua influência sobre a equidade no acesso ao ensino superior ${ }^{3}$. Baptista et al. (2013) avaliaram que, no geral, o programa foi positivo para melhorar as universidades federais, mas no período analisado havia poucos estudos em profundidade sobre o Reuni, não sendo possível determinar uma posição clara sobre o sucesso do programa, haja vista seus objetivos, de modo que justificasse sua eventual continuidade.

O Gráfico 1 evidencia a expansão das IES privadas após 1998. Ao contrário das públicas, onde as vagas ofertadas são praticamente todas preenchidas, nas IES privadas há sobra de vagas em grande proporção: 54\% em 2012; nas públicas, o nível de ocupação de média no ingresso é de $90 \%$. Se todas as vagas oferecidas no ensino superior fossem ocupadas, haveria um excesso de demanda de aproximadamente $30 \%{ }^{4}$, mas pela ineficiência na ocupação de vagas, apenas $59 \%$ são preenchidas, ampliando o excesso de demanda para quase $60 \%$. 


\section{Gráfico 1}

IES Públicas e Privadas: Vagas Oferecidas, Inscritos em

Processo Seletivo e Ingressos

(1980-2011)

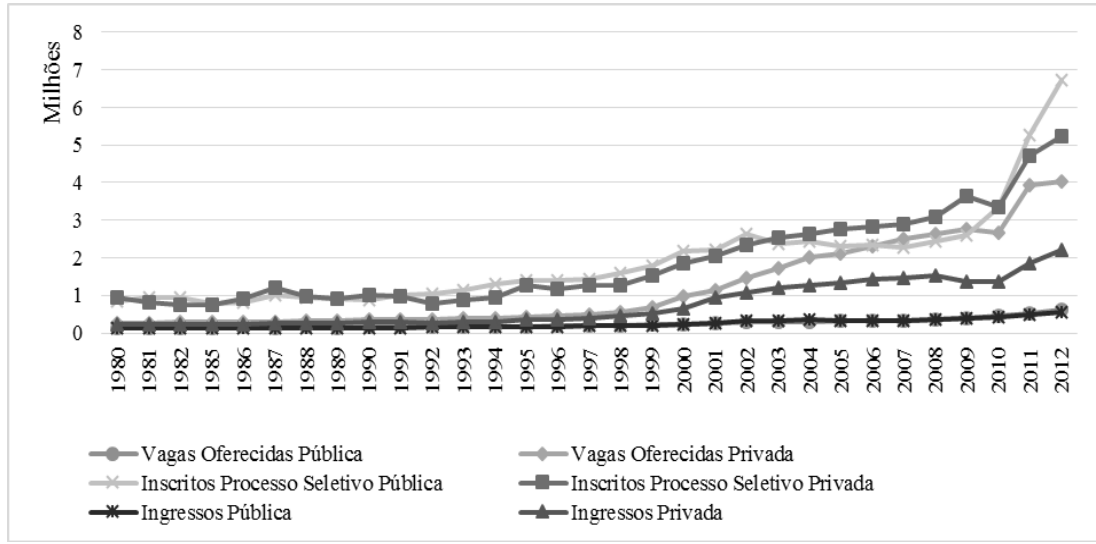

Fonte: Elaborado pelos autores a partir de Inep (2014b).

O descasamento entre o número de ingressantes no ensino superior com a quantidade de vagas oferecidas e a demanda por meio de processo seletivo poderia ter explicações diversas. Há ao menos quatro explicações para esta ineficiência: (a) os candidatos não apresentam um mínimo de proficiência demandado nos processos seletivos, então a qualidade do ensino médio seria a principal preocupação ${ }^{5}$; (b) haveria uma assimetria de informações pelo lado da oferta, que levasse as IES privadas a ofertarem vagas em excesso para cursos em que não há demanda ${ }^{6}$; (c) há grande quantidade de alunos prestando vários processos seletivos ao mesmo tempo; (d) os alunos passam no processo de seleção, mas não têm condições de assumir a vaga por falta de recursos financeiros. Estas situações podem acontecer ao mesmo tempo e é de particular interesse deste artigo discutir o último caso.

Os dados apresentados no Gráfico 2 mostram a distribuição da renda em termos de salários mínimos para os anos do ciclo de avaliação do Enade $^{7}$ de 2008 a 2010. No ano de 2008, o questionário socioeconômico que os alunos respondiam contemplava faixas de renda diferentes dos demais anos. Por isso, grande parte dos alunos encontra-se na classificação de 3 a 10 salários, que é, na verdade, um intervalo muito grande, incluindo em uma mesma categoria indivíduos muito diferentes. Nos demais anos observa-se mais claramente um padrão: as IES públicas dão mais oportunidades que as privadas, e isto pode ser reflexo das po- 


\section{Gráfico 2}

Distribuição de Renda Domiciliar dos Alunos, por IES, em Salários Mínimos Enade 2008-2010

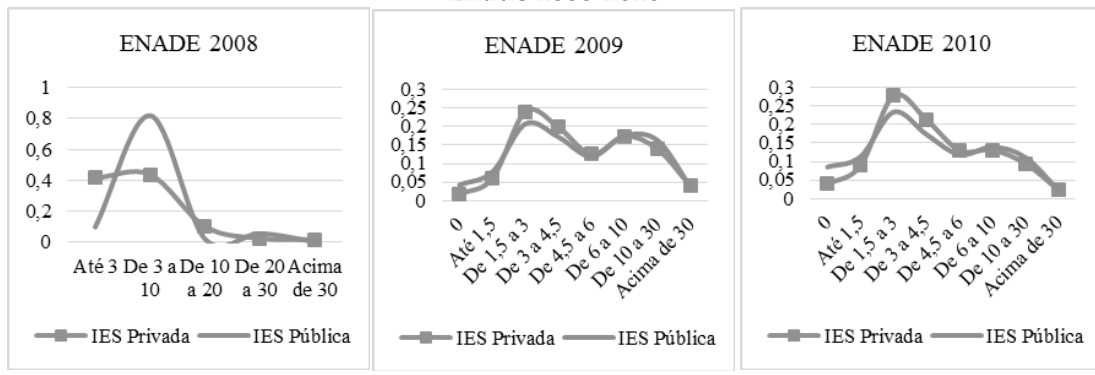

Fonte: Elaborado pelos autores a partir de Inep (2014a).

líticas de ação afirmativa já em vigor. No entanto, nas públicas também estão mais presentes as classes mais ricas. A representação da renda como condição deve ser relativizada nestes gráficos, pois considera também a renda do trabalho do aluno (Inep, 2014a).

O trabalho é uma característica do aluno médio, mas se observa que os alunos das IES privadas despendem mais horas de trabalho que os das públicas. A proporção de alunos que trabalham mais de 40 horas na semana em IES privadas é em média $80 \%$ superior à proporção dos que trabalham em públicas nos anos avaliados. O trabalho, enquanto oportuniza experiências de vida e aprendizagem ao aluno, é positivo; no entanto, pode representar um aspecto negativo quando for uma necessidade imposta ao aluno, como único meio de financiar sua educação. Apesar de implicar o complemento da renda, as horas de trabalho diminuem o tempo disponível para atividades acadêmicas e podem impactar negativamente sobre a qualidade do ensino (Inep, 2014a). De fato, uma análise de regressão simples indica correlação negativa entre notas do Enade e horas trabalhadas.

Políticas de compensação das condições socioeconômicas para aumentar a equidade de acesso ao ensino superior são relativamente recentes e ainda alcançam uma parte diminuta de alunos. Na Tabela 1 contabiliza-se a quantidade de alunos que em 2012 se beneficiavam com algum tipo de financiamento estudantil ou bolsa, cujas fontes financiadoras são desde as próprias IES privadas, como governos estaduais, municipais, até instituições estrangeiras. $13,6 \%$ dos alunos recebiam benefício estatal tipo bolsa ou financiamento. As cotas em IES públicas alcançavam mais $2,8 \%$ dos alunos, resultando em $16,4 \%$ do alunado que recebia 
Cristina B. de Souza Rossetto e Flávio de Oliveira Gonçalves

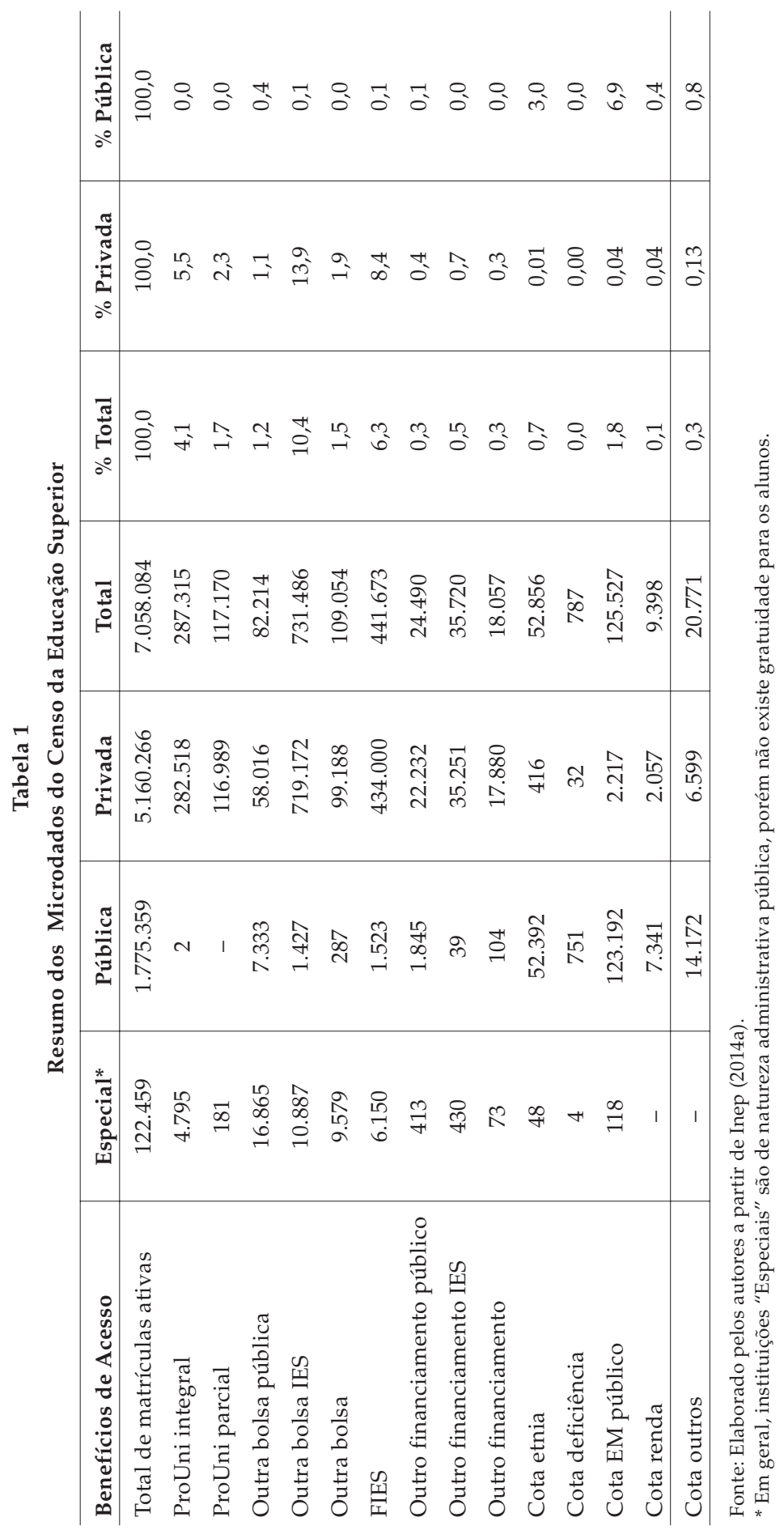

804 DADOS - Revista de Ciências Sociais, Rio de Janeiro, vol. 58, no 3, 2015 
algum apoio estatal para cursar o ensino superior. As IES privadas ofereceram incentivos (bolsas, financiamentos e cotas) a $11 \%$ do alunado total.

Uma questão relevante é se esses subsídios, incluindo a gratuidade nas IES públicas para quem não é cotista, seguem algum critério que torne as políticas coerentes entre si e com princípios de justiça.

\section{SUBSÍDIOS PÚBLICOS E EQUIDADE DE ACESSO NA ENTRADA NO ENSINO SUPERIOR}

Existem quatro grandes grupos que recebem subsídios públicos para acessar o ensino superior. Alunos em IES públicas são beneficiados, quando gratuitas; dividindo-se entre cotistas e não cotistas. Outros dois grupos são os beneficiários do ProUni e do FIES nas IES privadas ${ }^{8}$. Na Tabela 1 é possível observar que, além de 1,77 milhão de alunos em IES públicas, nas privadas cerca de 830 mil recebiam subsídios públicos por meio dos programas mencionados (Inep, 2014a). A questão que se propõe analisar é se essas diferentes formas de subsídio são coerentes entre si e seguem critérios que gerem igualdade de oportunidades.

Alunos de IES públicas não cotistas, em geral, são alunos com alto desempenho acadêmico; são alunos que se beneficiaram de condições superiores nas fases precedentes do ensino, o que lhes permite vantagens de competição pelas vagas nas públicas (Inep, 2014a). O subsídio destinado a pessoas em condições superiores não está de acordo com as proposições do conceito de igualdade de oportunidades.

A política de cotas, em princípio, está de acordo com a teoria de igualdade de oportunidades, pois focaliza grupos sociais considerados em desvantagem. Existem diversos trabalhos, tais como Pereira (2013), que discutem os impactos das cotas sobre a qualidade ou até mesmo sua legitimidade. Não é nosso objetivo aqui tratar desses temas. Além disso, dada a Lei no 12.711 de 2012, justifica-se um estudo específico para avaliar as mudanças sobre o perfil socioeconômico dos alunos das IES federais e as potenciais implicações sobre sua qualidade ${ }^{9}$. Para os fins deste artigo é importante mencionar que, antes da referida lei, cada IES tinha um conjunto de critérios diferente para direcionar as vagas, dando diferentes pesos às condições econômicas, raça, proveniência do Ensino Médio etc. Anova lei unificou a regra em âmbito federal e propôs um novo direcionamento da política, pelo qual o critério "Ensino Médio público" tornou-se o principal, seguido de renda e cor. Uma 
questão que se pode levantar é que a política de cotas não propõe uma gradualidade de subsídios, havendo gratuidade plena se o aluno for contemplado pela política.

O FIES, criado em 1999, oferece uma taxa de juros subsidiada a famílias com renda mensal de até 20 salários mínimos ${ }^{10}$. Desde 2005 o FIES também financia alunos do ProUni que recebem bolsas parciais. Em 2009 o FIES passou por uma grande reformulação, tornando-se um programa muito diferente do anterior no seu modus operandi e suas regras de contratação. Essa grande mudança ocorreu justamente no período avaliado no exercício empírico, no entanto, o método ou o período da coleta não parecem suficientes para produzir resultados que representem a atual realidade do FIES. Dessa forma, o que se pode melhor apresentar é uma retrospectiva do FIES.

A Controladoria Geral da União (2014) e o Tribunal de Contas da União (2009) apontaram dificuldades de gestão ao longo da história do FIES. O programa apresentou resultados pouco expressivos na maior parte da sua existência, tendo celebrado cerca de 530 mil contratos em seus primeiros dez anos. O FIES era de difícil acesso para as pessoas em piores condições de vida, porque exigia fiador em todos os contratos e não possibilitava $100 \%$ de financiamento. Além disso, havia falta de transparência, eficiência e rigor no cumprimento das regras. Pesava o alto nível de inadimplência e a instabilidade financeira que isto gerava para as instituições financiadoras solidárias no risco do crédito.

Em 2009, o Fundo Nacional de Desenvolvimento da Educação (FNDE) recebeu a gestão do FIES. Dentre outras ações, criou mecanismo para financiamento sem fiador de até $100 \%$ do custo $^{11}$. Segundo o FNDE (2014), 2012 e 2013 foram anos excepcionais, com 556 mil novos contratos apenas em 2013, totalizando 1,16 milhão de contratos ativos.

Enquanto a renda é o principal indicador para direcionar o subsídio do FIES, pode-se dizer que atualmente seu desenho está de acordo com os critérios de equidade propostos. No entanto, a política também favorece alunos que escolhem determinados cursos, considerados estratégicos ou prioritários. Esse critério não se justifica pela concepção de equidade sugerida, mas pode ser compreendido a partir de outras proposições do papel da política pública, como a de investir em áreas nas quais os benefícios privados são baixos, mas os sociais são altos. 
Conforme a Tabela 1, em 2012 o FIES não era a forma mais importante de compensação demandada pelos alunos da rede privada, mas é possível que o ritmo de crescimento recente se mantenha e o programa alcance proporções majoritárias. No que diz respeito às formas de subsídio público, o FIES é provavelmente a que oferece menor dificuldade de acesso, mas ainda é a mais custosa, comparando com as possibilidades de educação gratuita.

Em 2004 nasceu o ProUni, que beneficia os melhores alunos dos processos seletivos com bolsas integrais, quando possuem renda familiar per capita de até um salário mínimo e meio, e bolsas parciais para renda per capita de até três salários mínimos. O programa tem se tornado cada vez mais popular, com o número de inscritos permanentemente crescente, superando a quantidade de ingressos no ano de 2011. No ano do lançamento, 422,5 mil alunos interessaram-se pelo ProUni e quase 1,5 milhão em 2013. Porém, a proporção de bolsas ofertadas em relação aos ingressos não cresceu na mesma proporção que a demanda: o total de bolsas concedidas em 2005 foi de $8 \%$ dos ingressos, e permaneceu em cerca de 10\% entre 2008 e 2012 (últimos dados disponíveis). Do total de bolsas ofertadas, a participação das bolsas parciais foi em média de $42 \%$ do total. Em termos absolutos, foram 164,3 mil bolsas integrais e 87,9 mil parciais em 2013 . No primeiro ano do programa o total de bolsas ofertadas foi de 112,2 mil (ProUni, 2014; Inep, 2014b).

O ProUni, apesar de ter ampliado a equidade de acesso ao ensino superior, não está exatamente alinhado com a ideia de igualdade de oportunidades, pois combina critérios de esforço com condição. Não é possível afirmar que estes alunos não teriam outras oportunidades de acesso sem a política, dado que são alunos com alto desempenho escolar. No entanto, a maior crítica que se pode fazer ao ProUni diz respeito ao seu desenho: não é possível uma expansão ad infinitum das bolsas, porque elas são concedidas em proporção ao montante de desoneração fiscal possível para cada IES.

Com relação à coerência entre os programas, pode-se apontar o fato de que as cotas usam, em geral, três características como condição - ensino médio público, renda e raça -, enquanto o ProUni não traz o critério de raça e o FIES tem apenas o critério de renda. O critério esforço é necessário, em alguma medida, para as cotas e essencial para o ProUni. Esses critérios diferentes são compreensíveis dados os contextos históricos em que cada política foi criada, mas o policy maker poderá no futu- 
ro pensar em uma única política de destinação dos subsídios públicos, guiada por um único critério (que pode ser multidimensional).

\section{AVALIAÇÃO DA EQUIDADE DAS OPORTUNIDADES DE ACESSO AO ENSINO SUPERIOR POR UM MODELO LOGIT MULTINOMIAL}

Para testar e verificar empiricamente a relevância de variáveis de condição e esforço sobre as possibilidades de acesso ao ensino superior, realizou-se um exercício econométrico, a partir de um modelo logit multinomial. Este modelo tem como uma de suas principais características o fato de a variável dependente ser uma variável categórica. No caso do modelo aqui apresentado, há seis categorias distintas, que representam as escolhas dos indivíduos: IES pública sem cotas (categoria-base), IES pública com cotas, IES privada sem benefícios, IES privada com ProUni, IES privada com FIES e IES privada com outros benefícios. São essas as categorias consideradas na variável dependente.

O estimador do modelo mostra a probabilidade de o indivíduo pertencer à categoria $i$, comparando com sua chance de pertencer à categoria de base. Conforme Cameron e Trivedi (2005:500), o estimador da probabilidade é

$$
p_{i j}=e^{X I_{i} \beta_{j}} / \sum_{l=1}^{m} e^{X I_{i} \beta_{j}} \quad j=l, \ldots, m
$$

Uma restrição deste modelo é supor que a razão de probabilidades entre escolher entre duas alternativas de um conjunto de alternativas $\mathrm{A}$ é independente dos atributos ou da existência de outras alternativas (ibidem). Esta suposição é bastante forte para o caso que se está avaliando, pois implica dizer que os alunos não têm ordem de preferência em relação às alternativas propostas no modelo. No entanto, na medida em que o custo de estudar varia para cada categoria, seria possível considerar um modelo de preferências ordenadas. Entretanto, não é tão simples identificar esta ordem de preferência, uma vez que alguns indivíduos têm acesso a todas as categorias e outros não (por exemplo, alunos de alta renda não têm acesso a cotas ou ProUni). Assim, optou-se por manter o modelo não ordenado como uma abordagem exploratória, ainda que seja uma forma restrita de representar o problema.

Interessa observar se as variáveis de condição apontam desvantagens para grupos de alunos cujos custos educacionais sejam mais altos. Por exemplo, alunos de IES públicas têm custo zero e alunos das privadas sem benefícios arcam com as mensalidades. Se os alunos das priva- 
Tabela 2

Variáveis Explicativas do Modelo Logit Multinomial

\begin{tabular}{|c|c|c|}
\hline Variáveis de Condição & Nome da Variável & Descrição \\
\hline Renda & $\begin{array}{l}\text { renda1, renda2, } \\
\text { renda3 e renda } 4\end{array}$ & $\begin{array}{l}\text { Renda domiciliar em termos de } \\
\text { salários mínimos. Para o ano } \\
\text { de } 2008 \text { : renda } 1=3 \text { a } 10 \\
\text { salários mínimos (sm); renda2 } \\
\text { = } 10 \text { a } 20 \mathrm{sm} \text {; renda } 3=20 \text { a } 30 \\
\text { sm; renda } 4=\text { mais de } 30 \mathrm{sm} \text {. } \\
\text { Para os anos de } 2009 \text { e } 2010 \text { : } \\
\text { renda } 1=3 \text { a } 6 \text { sm; renda } 2=6 \text { a } \\
10 \mathrm{sm} \text {; renda3 = } 10 \text { a } 30 \mathrm{sm} ; \\
\text { renda } 4=\text { mais de } 30 \text { sm. A } \\
\text { categoria-base é sempre renda } \\
\text { até } 3 \text { sm }\end{array}$ \\
\hline $\begin{array}{l}\text { Número de pessoas no } \\
\text { domicílio }\end{array}$ & nfam & \\
\hline Pessoa com deficiência & defic & $\begin{array}{l}\text { Pessoa com } 1 \text { ou mais tipos de } \\
\text { deficiência }\end{array}$ \\
\hline Sexo & sexo_hom & $1=$ homens, $0=$ mulheres \\
\hline Cor & $\begin{array}{l}\text { negro_índio e } \\
\text { pardo }\end{array}$ & $\begin{array}{l}\text { Categoria-base: brancos e } \\
\text { amarelos }\end{array}$ \\
\hline $\begin{array}{l}\text { Escolaridade dos pais } \\
\text { Ensino médio em escola } \\
\text { privada }\end{array}$ & $\begin{array}{l}\text { escpai e escmae } \\
\text { med_priv }\end{array}$ & $\begin{array}{l}1=\text { médio privado, } 0=\text { médio } \\
\text { público }\end{array}$ \\
\hline Variáveis de Esforço (escolha) & Nome da Variável & Descrição \\
\hline Estado civil & solteiro & $1=$ solteiro, $0=$ outros \\
\hline Horas de estudo & $\begin{array}{l}\text { estuda4a12h e } \\
\text { estuda_mais12h }\end{array}$ & $\begin{array}{l}\text { Categoria-base }=\text { estuda de } 0 \text { a } \\
4 \text { horas na semana }\end{array}$ \\
\hline $\begin{array}{l}\text { Participação em atividades } \\
\text { acadêmicas }\end{array}$ & ativ_acad & $\begin{array}{l}1=\text { participa, } 0=\text { não participa } \\
\text { Participação em ao menos uma }\end{array}$ \\
\hline Trabalho & $\begin{array}{l}\text { trab_ate20, } \\
\text { trab20a40, } \\
\text { trab_mais40 }\end{array}$ & $\begin{array}{l}\text { atividade como iniciação } \\
\text { científica, extensão, monitoria } \\
\text { etc. } \\
\text { Horas semanais trabalhadas } \\
\text { Categoria-base: não trabalha }\end{array}$ \\
\hline
\end{tabular}

Fonte: Elaboração dos autores.

das estiverem em condições piores que os das públicas, então isso indica uma desigualdade de oportunidades.

Na Tabela 2 estão descritas as variáveis explicativas. Foram utilizados os microdados do Enade de 2008 a 2010 somente para os ingressantes. É necessário considerar os três anos, porque em cada um deles são avaliados conjuntos distintos de cursos, concluindo um ciclo a cada três 
anos. Como os dados do último ciclo ainda não estão disponíveis, optou-se por utilizar o ciclo anterior. É importante considerar que até 2008 o Enade era amostral e tornou-se censitário a partir de 2009 (IBGE, 2014).

Conforme os microdados, em 2008 realizariam a prova mais de $825 \mathrm{mil}$ alunos, enquanto em 2009 seria 1,1 milhão, e 650.450 em 2010. Porém, somente 166.556 dos ingressantes responderam ao questionário socioeconômico em 2008; 325.923 em 2009 e 163.701 em 2010, totalizando 656.180 alunos ingressantes. O número final de observações foi de 581.881 , pois o software (Stata) descarta indivíduos que não apresentem dados para todas as variáveis do modelo (missings).

Uma limitação da variável renda é que ela inclui a renda do trabalho do aluno, tornando difícil separar condição e esforço. Outra crítica relevante é que se observam apenas indivíduos que de fato acessam o ensino superior. Isto gera restrições na avaliação das oportunidades de acesso e possivelmente os resultados apresentados estão subestimados. Esta subestimação se dá porque não se observam os indivíduos que tentaram acessar e não conseguiram (censura) e também porque não observamos aqueles que nem tentaram e gostariam de acessar, tampouco aqueles que poderiam acessar, mas não desejam. Estes últimos dois casos implicam viés de seleção amostral.

Os resultados apresentados na Tabela 3 mostram a razão de probabilidade (odds ratio), ou seja, a mudança proporcional que ocorre na probabilidade na categoria em questão, em relação à categoria-base, quando a variável exógena muda em uma unidade (Cameron e Trivedi, 2005). A categoria "privada com outros benefícios" foi omitida, porque não é objeto de interesse e serviu como controle.

Na Tabela 3, considera-se que valores abaixo de 1 indicam maior chance de pertencer à categoria-base; valores acima de 1 indicam maior chance de pertencer à categoria de comparação. Por exemplo, considere-se a variável "escmae" na primeira coluna: um ano a mais de escolaridade da mãe está associado a uma redução de 3\% $(1-0,97)$ na probabilidade de o indivíduo ser cotista em uma IES pública, diante de sua chance de ser não cotista. Em outras palavras, filhos de mães com melhor nível de escolaridade têm mais chances de serem não cotistas.

O conjunto de variáveis exógenas contempla não somente variáveis contínuas, como escmae, mas variáveis categóricas, o que demanda mais cuidado na interpretação. Tome-se "homem" na primeira coluna 
Equidade na Educação Superior no Brasil

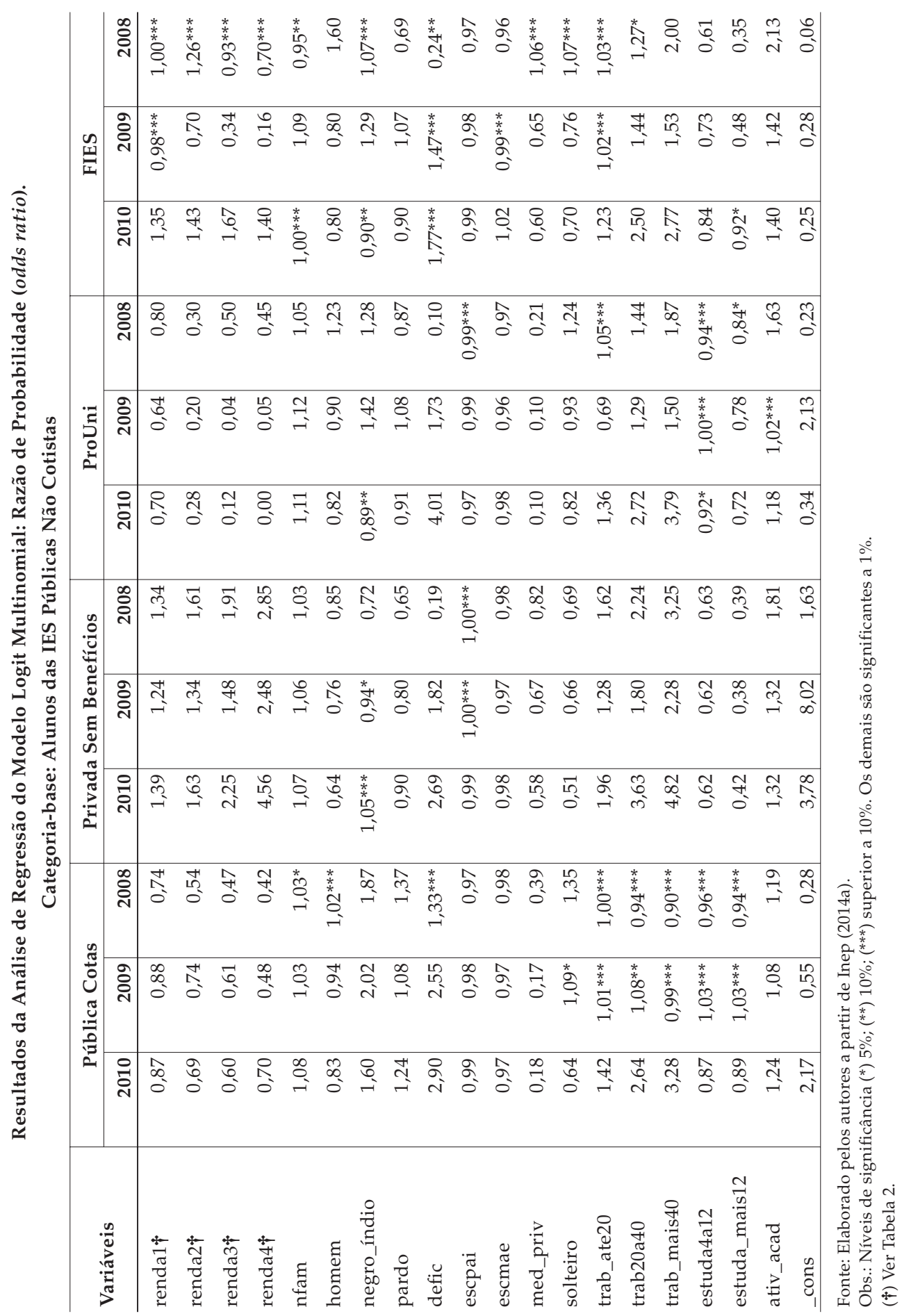

DADOS - Revista de Ciências Sociais, Rio de Janeiro, vol. 58, nํ 3, 2015 
da Tabela 3. Esta variável está em comparação com "mulher", além de referir-se à categoria-base (não cotista em IES pública). Assim, o homem tem $17 \%$ a menos de chance $(1-0,83)$ que a mulher de ser cotista a ser não cotista.

No caso de renda, a base são indivíduos com renda familiar até 3 salários mínimos. Tomando a primeira coluna da Tabela 3, cotistas de renda1 (entre 3 e 6 salários mínimos) tinham 13\% (1-0,87) a menos de chance de que alunos com renda até 3 salários de serem cotistas, frente a serem não cotistas. O modelo não mostra qual a probabilidade do indivíduo da categoria zero da variável renda, porém importante é notar que, conforme aumenta a renda, a probabilidade de o indivíduo ser cotista (frente a ser não cotista) cai - e esse é o fato mais importante para esta análise.

A análise empírica traz diversas informações interessantes sobre os ingressantes do ensino superior, no entanto, optou-se em discutir apenas aquelas com potencial de impactar sobre o atual desenho da política pública. Busca-se observar se há desvantagem de competição, haja vista os custos de estudar.

Bolsistas integrais do ProUni têm educação gratuita, como não cotistas em públicas. No entanto, quase metade dos alunos do ProUni recebe bolsas parciais. Portanto, para os resultados apresentados, alunos no ProUni não têm educação gratuita, na média. Desta forma, dadas as condições piores desses alunos, ainda que trabalhassem mais, a política não era equitativa considerando que alunos em melhores condições têm ensino gratuito nas IES públicas.

O FIES é um programa de difícil análise. Em 2009 as variáveis de renda apontavam para desvantagem desse grupo comparando ao da categoria-base, mas esse resultado é oposto em 2010. As outras variáveis de condição também mostram ambiguidades. Talvez esta mudança de perfil seja reflexo das mudanças institucionais ocorridas no programa em 2009, mas é necessário estudo com metodologia apropriada para buscar essa causalidade. De todo modo, em 2010, quando parece que a renda dos alunos do FIES é superior à da categoria-base, também é maior o diferencial em termos de pessoas que trabalham. Os resultados mostram que não houve no período uma definição clara do público-alvo do programa, o que justifica reformas sobre o desenho da política na sua focalização e objetivos.

Alunos que acessaram o ensino superior por meio de cotas no período tinham condições piores que os não cotistas, indicando boa focaliza- 
ção da política. No entanto, pode indicar desigualdade de condições o fato de que cotistas trabalhavam mais que não cotistas. Uma pergunta importante é o quanto o trabalho é essencial para a permanência desses alunos no ensino superior.

A comparação entre públicas sem cotas e privadas sem benefícios mostra que a renda dos alunos das privadas era superior, porém em outras variáveis de condição eram piores: são alunos que tiveram menos acesso ao ensino médio privado e com pais com nível de escolaridade mais baixo. No quesito esforço, apesar de gastarem menos horas estudando na semana, atuam mais academicamente. É marcante a diferença na variável de tempo dedicado ao trabalho. Definitivamente, prejudica a análise o fato de ser impossível separar da variável renda os ganhos do trabalho dos alunos. A mesma pergunta se aplica com relação ao papel da renda do trabalho sobre a permanência desses alunos no ensino superior.

É possível fazer outras comparações, dividindo o resultado de uma coluna por outra na mesma linha. Há evidência de inadequação da política quando comparados cotistas e prounistas. Como a política de cotas aceita mais alunos de maior renda que o ProUni, então prounistas têm renda pior, apesar de trabalharem mais (em 2009 e 2010); prounistas também tiveram menos chances de cursar ensino médio privado. Como discutido, alunos do ProUni não têm, em média, educação gratuita, como os cotistas. Os resultados mostram que as cotas favoreceram indivíduos cujas causas de inequidade estejam mais associadas à cor. Esta constatação é importante, pois implica dizer que naquele período houve um peso maior da cor para recebimento de benefícios públicos do que as condições econômicas (e demais variáveis de condição). Isto não parece ser o direcionamento da política atual de cotas (nas IES federais, ao menos), que destina mais vagas pelo critério de renda que pelo critério de cor. Um índice multidimensional, com pesos claramente estabelecidos, e que fosse aplicado a todos os alunos (uma única "régua"), seria uma estratégia mais transparente de determinação dos benefícios a que cada um teria direito, dados os custos de estudar.

\section{POSSIBILIDADES DE REFORMA PARA UM SISTEMA EDUCACIONAL MAIS EQUITATIVO}

As seções anteriores mostraram evidências de injustiça distributiva no acesso ao ensino superior no Brasil, pelo conceito de igualdade de 
oportunidades. Alunos com condições piores têm custos maiores de educação em algumas circunstâncias. O objetivo desta seção é discutir direcionamentos para a política pública, sem pretender que sejam solução única e conclusiva.

A OECD (2008) propõe os seguintes direcionamentos de política pública: avaliar a extensão e as origens dos problemas de equidade, fortalecer a integração entre o planejamento dos sistemas secundário e terciário, considerar políticas de ação afirmativa para grupos particulares, cujas desvantagens educacionais estejam bem identificadas, incrementar o suporte para alunos provenientes de piores situações socioeconômicas.

No Brasil, diversos estudos empíricos diagnosticam determinantes das desigualdades educacionais nas diversas etapas de formação, e alguns (em menor quantidade) focam o problema da transmissão das desigualdades no decorrer do processo educacional, como Ribeiro (2011). Como apontam esses estudos, discutir políticas de equidade apenas no ensino superior é insuficiente; é imprescindível um olhar compreensivo do processo educacional.

Precede a discussão de equidade aquela sobre a quantidade de vagas. Evidenciou-se que a ampliação das vagas é um direcionamento de política, dado o excesso de demanda. No entanto, sem melhorar a eficiência no uso das vagas já disponíveis, torna-se absurdo pensar somente em ampliação.

Ainda que faltem vagas, é possível tornar o processo de ingresso mais equitativo. O conceito de igualdade de oportunidades sugere que haja subsídios públicos para os indivíduos em desvantagem de condições. Assim, por exemplo, a gratuidade ou bolsas estariam acessíveis a todos os alunos até uma determinada condição de vida, considerada inferior, segundo um indicador escolhido (pode ser renda ou algum indicador multidimensional). Gradualmente o apoio se reduz, conforme melhoram as condições dos indivíduos.

A interpretação sugerida de igualdade de oportunidades para o ensino superior não é contra a gratuidade, em princípio, mas é um constrassenso as IES públicas aceitarem alunos de alta renda que não pagam mensalidades, bem como alunos pobres nas privadas que pagam. Duenhas (2013) debate a questão da gratuidade na rede pública e sugere, entre outras coisas, o compartilhamento dos custos entre a esfera pública e a privada. 
Argumentos contra a gratuidade no ensino superior apontam que boa parte da renda futura gerada é apropriada somente pelos indivíduos e não por toda a sociedade. Então, não faria sentido toda a sociedade financiar por um ganho que é majoritariamente privado (Barr, 2004). A diferença, então, da proposta anterior, é que, ao invés de oferecer ensino gratuito, todos os alunos que solicitassem seriam financiados pelo governo, que cobraria taxas de juros crescentes com a renda; a gratuidade seria exceção (a critério de cada IES).

Num sistema em que o custo de acessar uma vaga, seja na rede pública, seja na privada, corresponde à condição do aluno, é possível vislumbrar um novo tipo de competição emergindo no ensino superior no Brasil: pela qualidade. É natural que sejam percebidos graus distintos de qualidade entre uma IES e outra, pelos atributos do seu corpo docente, pela infraestrutura que oferece, pela sua inserção na comunidade científica etc. A gratuidade do ensino público, no sistema de incentivos atual, distorce esse mecanismo de competição dos alunos pelas melhores IES (ou das IES pelos melhores alunos). Sem a restrição econômica, o processo de competição teria outra configuração.

As discussões de política de equidade, como Holsinger e Jacob (2008), iriam no sentido de avaliar quais sistemas de financiamento são mais ou menos inclusivos. A literatura neste sentido é relativamente ampla, uma vez que é tema bastante recorrente na maioria dos países europeus e nos EUA, onde normalmente a educação não é gratuita, ainda que pública em diversos casos.

\section{CONSIDERAÇÕES FINAIS}

O objetivo deste artigo foi discutir políticas de equidade de acesso ao ensino superior no Brasil, mais especificamente cotas, ProUni e FIES. A partir de análise empírica, o propósito era verificar se havia coerência dessas políticas entre si, ou seja, se elas propõem regras iguais de acesso para pessoas em iguais condições e se estas regras estão de acordo com as proposições dos princípios de igualdade de oportunidades.

A existência de programas como o ProUni, o FIES e as ações afirmativas nas IES públicas são avanços na direção de um sistema mais equitativo. No entanto, estas políticas atendem a um universo reduzido dos alunos matriculados no ensino superior, cerca de 17\% em 2012 (Inep, 2014a), e põem em dúvida o quanto possam impactar na redução da desigualdade de oportunidades no acesso ao ensino superior. Isso porque o volume 
de subsídios não é designado a partir de um conhecimento das demandas pelo ensino superior e das condições de acesso dos indivíduos.

A construção das políticas de equidade do ensino superior não foi articulada de forma integrada, resultando inadequações, ineficiências e ambiguidades diante de um propósito de gerar maior justiça distributiva. A análise empírica evidenciou que, ainda que acessem as políticas mencionadas, alunos arcam com custos desproporcionais às suas condições. É importante mencionar que há limitações da base que implicam viés de estimativa.

Programas como o ProUni, o FIES e as cotas trazem maior diversidade socioeconômica ao ambiente acadêmico, mas propõem critérios diferentes entre si para focalizar os grupos beneficiários da política. Comparando com alunos não cotistas em IES públicas, parte desses alunos está em desvantagem de condição e não tem educação gratuita. Além disso, existem subsídios associados a características de esforço, o que é questionável em princípio pelo conceito de igualdade de oportunidades apresentado.

A questão do trabalho deve ser melhor investigada, pois talvez seja condição essencial para manutenção dos alunos nas instituições pagas, inclusive para alunos que não são elegíveis para nenhuma política de acesso. A orientação básica da política, segundo o conceito de igualdade de oportunidades, é que é necessário tornar os custos do ensino superior correspondentes às condições dos alunos: aqueles em piores condições deveriam receber mais benefícios públicos. Assim, a concorrência por uma vaga seria definida pelo esforço e não por outras características, sobre as quais os indivíduos não têm controle.

A existência da gratuidade nas IES públicas é uma questão importante no Brasil, que não está em contradição com o conceito de equidade proposto, em princípio. Mas há argumentos contra esta política, a partir de trabalhos empíricos, que mostram que o retorno social deste investimento é menor que o retorno privado. Consequentemente, os custos devem ser majoritariamente privados e não sociais. Não é defensável sob a teoria a gratuidade para pessoas em melhores condições socioeconômicas e o alto custo para aqueles em desvantagem.

Numa situação ideal, não haveria restrição de vagas no ensino superior. Porém, faltam vagas e, então, os alunos precisam contar não somente com as políticas compensatórias, mas com o próprio esforço. Se 
o custo de uma vaga, independente da IES, fosse correspondente às condições dos alunos, possivelmente se ampliaria o processo competitivo entre as IES em busca de melhor qualidade. No modelo atual, esse processo segue influenciado pelos diferenciais de custos entre IES públicas e privadas, privilegiando as primeiras.

A ampliação das políticas de acesso deverá implicar no Brasil o aprofundamento das discussões sobre o financiamento do ensino superior como um todo; sobre como integrar melhor as etapas de formação, para que as desigualdades se reduzam a cada fase; sobre os critérios e princípios que representem a visão da sociedade de justiça distributiva etc. Existe no mundo grande diversidade de arranjos de políticas educacionais, já amplamente discutidos academicamente, os quais poderão oportunamente servir como ponto de apoio para o debate nacional.

(Recebido para publicação em maio de 2014)

(Reapresentado em fevereiro de 2015) (Aprovado para publicação em junho de 2015) 


\section{Cristina B. de Souza Rossetto e Flávio de Oliveira Gonçalves}

\section{NOTAS}

1. Há IES “especiais", geralmente estaduais e municipais que não são gratuitas.

2. Busca em scholar.google.com.br gera mais de 15 mil resultados para "cotas + afirmativa"; "ProUni" e "FIES + financiamento" geram aproximadamente 7 mil resultados somados.

3. Não foram encontrados artigos científicos tratando dos impactos gerados pelo Reuni sobre a equidade no acesso ao ensino superior.

4. Não existe um dado exato sobre demanda pelo ensino superior. Este valor de $30 \%$ foi aproximado, tomando a quantidade de inscritos em processos seletivos nas públicas, os mais procurados, com 6,7 milhões de inscritos em 2012. Considera-se que a população demandante da rede pública é a mesma da rede privada, não fazendo sentido somar as inscrições nas duas redes. Se fosse somada a quantidade de inscritos, haveria quase 12 milhões de pessoas buscando o ensino superior e o gap entre oferta e demanda seria ainda muito maior do que os $30 \%$ sugeridos.

5. Relatório Pedagógico do Enem de 2008 (Inep, 2009) aponta que esta é uma questão pertinente.

6. Em 2010 o governo federal criou o Sistema de Seleção Unificada (Sisu), que permite que candidatos do Enem concorram a vagas em diversas IES públicas ao mesmo tempo, gerando melhor aproveitamento das vagas oferecidas. Esta nota vale também para o caso (c).

7. Dados do último ciclo não estão disponíveis. Os cursos avaliados no Enade ciclo 2008-2010 são: (2008) - Arquitetura e Urbanismo, Biologia, Ciências Sociais, Computação, Engenharia, Filosofia, Física, Geografia, História, Letras, Matemática, Pedagogia e Química, e os Cursos Superiores de Tecnologia em Alimentos, Análise e Desenvolvimento de Sistemas, Automação Industrial, Construção de Edifícios, Fabricação Mecânica, Gestão de Produção Industrial, Manutenção Industrial, Processos Químicos, Redes de Computadores e Saneamento Ambiental. (2009) - Administração, Arquivologia, Biblioteconomia, Ciências Contábeis, Ciências Econômicas, Comunicação Social, Design, Direito, Estatística, Música, Psicologia, Relações Internacionais, Secretariado Executivo, Teatro e Turismo, e os Cursos Superiores de Tecnologia em Design de Moda, Gastronomia, Gestão de Recursos Humanos, Gestão de Turismo, Gestão Financeira, Marketing e Processos Gerenciais. (2010) - Agronomia, Biomedicina, Educação Física, Enfermagem, Farmácia, Fisioterapia, Fonoaudiologia, Medicina, Medicina Veterinária, Nutrição, Odontologia, Serviço Social, Terapia Ocupacional e Zootecnia; tecnólogo em Agroindústria, Agronegócios, Gestão Hospitalar, Gestão Ambiental e Radiologia.

8. Não fazem parte dessa análise outras formas de benefício público, ofertadas por estados e municípios ou programas minoritários, bem como políticas recentes como o Sisu e o Reuni. Elas podem ter gerado impactos sobre a equidade no acesso no ensino superior, mas não são políticas designadas a grupos específicos.

9. Ainda não está disponível base de dados que permita avaliação quantitativa dessa política em âmbito nacional.

10. Até 2012 havia várias taxas de juros em vigor, de acordo com o curso. Atualmente a taxa é de 3,4\% para todos (SisFIES, 2014).

11. Estudantes em licenciaturas, ou com renda familiar mensal per capita de até um salário mínimo e meio, ou bolsistas do ProUni. 


\section{REFERÊNCIAS BIBLIOGRÁFICAS}

ALMEIDA, Aléssio Tony Cavalcanti de. (2014), “Determinantes dos Piores e Melhores Resultados Educacionais dos Alunos da Rede Pública de Ensino Fundamental no Brasil". Planejamento e Políticas Públicas, no 42, pp. 147-187.

ANDERSON, Elizabeth. (1999), “What Is the Point of Equality?”. Ethics, vol. 109, no 2, pp. 287-337.

ANDRADE, Cibele Yahn de; DACHS, J. Norberto W. (2007), “Acesso à Educação por Faixas Etárias segundo Renda e Raça/Cor". Cadernos de Pesquisa, vol. 37, no 131, pp. 399-422.

ANDRADE, Eduardo de Carvalho. (2007), "Effects of the Brazilian University Policy of Targeting the Poor". Estudos Econômicos, vol. 37, no 3, pp. 663-683.

APRILE, Maria Rita; BARONE, Rosa Elisa Mirra. (2009), “Educação Superior: Políticas Públicas para Inclusão Social". Revista Ambiente Educação, vol. 2, no 1, pp. 39-55.

ARAÚJO, Maria Arlete Duarte; PINHEIRO, Helano Diógenes. (2010), “Reforma Gerencial do Estado e Rebatimentos no Sistema Educacional: Um Exame do REUNI". Ensaio: Avaliação e Políticas Públicas em Educação, vol. 18, no 69, pp. 647-668.

ARROW, Kenneth; BOWLES, Samuel; DURLAUF, Steven (orgs.). (2000), Meritocracy and Economic Inequality. Princeton, Princeton University Press.

BAPTISTA, Carolinne Montes et al. (2013), O Estado da Arte sobre o Reuni. Trabalho apresentado no XIII Colóquio Internacional sobre Gestão Universitária nas Américas, Buenos Aires, 27-29 de novembro. Disponível em https:/ / repositorio.ufsc.br / handle/123456789/114850. Acessado em 24/11/ 2014.

BARONI, José Marcelo Biagioni. (2010), Acesso ao Ensino Superior Público: Realidade e Alternativas. Tese de Doutorado, Faculdade de Educação, Universidade de São Paulo, São Paulo.

BARR, Nicholas. (2004), “Higher Education Funding". Oxford Review of Economic Policy, vol. 20, no 2, pp. 264-283.

BARRETO, Ângela Rabelo; CODES, Ana Luiza; DUARTE, Bruno. (2012), “Alcançar os Excluídos da Educação Básica: Crianças e Jovens Fora da Escola no Brasil”. Série Debates Educação, no 3 .

BÉNABOU, Roland. (2000), "Meritocracy, Redistribution and the Size of the Pie", in K. Arrow; S. Bowles; S. Durlauf (orgs.), Meritocracy and Economic Inequality. Princeton, Princeton University Press, pp. 317-339.

BRASIL. Ministério da Educação. (2007), Plano de Desenvolvimento da Educação: Razões, Princípios e Programas. Disponível em http://portal.mec.gov.br/arquivos/livro/livro.pdf. Acessado em 20/11/2014.

CAMERON, A. Colin; TRIVEDI, Pravin K. (2005), Microeconometrics: Methods and Applications. New York, Cambridge University Press.

CGU (Controladoria-Geral da União). (2014), "Relatório de Auditoria Anual de Contas: Fundo de Financiamento ao Estudante do Ensino Superior - 2005 a 2012". Disponível em http://sistemas.cgu.gov.br/relats/relatorios.php. Acessado em 8/4/2014. 


\section{Cristina B. de Souza Rossetto e Flávio de Oliveira Gonçalves}

COHEN, Gerald Allan. (1989), “On the Currency of Egalitarian Justice”. Ethics, vol. 99, no 4, pp. 906-944.

CUNHA, Luiz Antônio. (2004), “Desenvolvimento Desigual e Combinado no Ensino Superior: Estado e Mercado". Educação \& Sociedade, vol. 25, no 88, pp. 795-817.

DILL, Helena; GONÇALVES, Flávio de O. (2012), “Igualdade de Oportunidade no Brasil entre 1999 e 2009: Estimação e Decomposição através do Valor de Shapley". Pesquisae Planejamento Econômico, vol. 42, no 2, pp.185-210.

DUENHAS, Rogério A. (2013), O Compartilhamento do Financiamento das Instituições Públicas de Ensino Superior. Tese de Doutorado, Programa de Pós-Graduação em Desenvolvimento Econômico, Universidade Federal do Paraná.

FLEURBAEY, Mark. (2008), Fairness, Responsibility, and Welfare. New York, Oxford University Press.

FNDE (Fundo Nacional de Desenvolvimento da Educação). (2014), Fies Supera Marca de 556 mil Contratos em 2013. Disponível em http://www.fnde.gov.br/fnde/ sala-de-imprensa/noticias/item/5154-fies-supera-marca-de-556-mil-contratosem-2013?highlight=YToxOntpOjA7czo0OiJmaWVzIjt9. Acessado em 20/3/2014.

GEMAQUE, Rosana M.; CHAVES, Vera Lucia. (2010), “Perfil da Expansão no Setor Público e Privado e Financiamento da Educação Superior Brasileira pós-LDB". Revista Série-Estudos - Periódico do Programa de Pós-Graduação em Educação da UCDB, no 30, pp. 71-91.

GONÇALVES, Flávio de O.; FRANÇA, Marco T. (2008), “Transmissão Intergeracional de Desigualdade e Qualidade Educacional: Avaliando o Sistema Educacional Brasileiro a partir do SAEB 2003". Ensaio: Avaliação de Políticas Públicas Educacionais, vol. 16, no 61, pp. 639-662.

HECKMAN, James; MOSSO, Stefano. (2014), “The Economics of Human Development and Social Mobility". Annual Review of Economics, vol. 6, no 1, pp. 689-733.

HOLSINGER, Donald; JACOB, W. James. (2008), Inequality in Education: Comparative and International Perspectives Comparative. Hong Kong, Education Research Centre.

IBGE (Instituto Brasileiro de Geografia e Estatística). (2014), Exame Nacional de Desempenho dos Estudantes - ENADE. Disponível em http://ces.ibge.gov.br/base-de-dados/metadados/inep/exame-nacional-de-desempenho-dos-estudantes-enade. Acessado em 20/3/2014.

INEP (Instituto Nacional de Estudos e Pesquisas Educacionais Anísio Teixeira). (2009), Relatório Pedagógico ENEM 2008. Disponível em http:/ / downloadinep.gov.br/educacao_basica/enem/relatorios_pedagogicos/relatorio_pedagogico_enem_ 2008pdf. Acessado em 13/4/2013.

. (2014a), Microdados para Download. Disponível em http:/ / portalinepgovbr/basica-levantamentos-acessar. Acessado em 8/3/2014.

(2014b), Sinopses Estatísticas da Educação Superior - Graduação. Disponível em http:// portalinepgovbr/superior-censosuperior-sinopse. Acessado em 8/4/2013. Acessado em 8/3/2014.

MAFFETONE, Sebastiano; VECA, Salvatore. (2005), A Idéia de Justiça de Platão a Rawls. São Paulo, Martins Fontes. 
MEC (Ministério da Educação). (2009), Programa de Apoio a Planos de Reestruturação e Expansão das Universidades Federais - Reuni 2008 - Relatório de Primeiro Ano. Disponível em http:/ / reuni.mec.gov.br/o-que-e-o-reuni. Acessado em 20/11/2014.

MITHAUG, Dennis E. (1996), Equal Opportunity Theory: Fairness in Liberty for All. London, Sage Publications.

MOEHLECKE, Sabrina. (2004), Fronteiras da Igualdade no Ensino Superior: Excelência \& Justiça Racial. Tese de Doutorado, Faculdade de Educação, Universidade de São Paulo, São Paulo.

NUNES, André. (2011), “As Teorias de Justiça e a Equidade no Sistema Único de Saúde no Brasil". Planejamento e Políticas Públicas, no 37, pp. 2-39.

OECD (Organisation for Economic Co-operation and Development). (2007), No More Failures: Ten Steps to Equity in Education. Disponível em http:/ / www.tpf.hu/document.php?doc_name=tudaskozpont/LLL_projekt/meltanyossag/10_Steps_ to_Equity_in_Education_oECD.pdf. Acessado em 10/3/2014.

. (2008), Tertiary Education for the Knowledge Society. Special Features: Equity, Innovation, Labour Market, Internationalisation. Volume 2. Disponível em http:// www.oecd.org/edu/skills-beyond-school/41266759.pdf. Acessado em 15/3/2014.

PEREIRA, Joaquim. (2013), Análise do Impacto da Implantação das Cotas na Nota Enade 2008. Dissertação de Mestrado, Universidade Federal do Paraná, Programa de PósGraduação em Desenvolvimento Econômico, Curitiba.

PRESIDÊNCIA da República - Casa Civil, Subchefia para Assuntos Jurídicos. (2012), Lei № 12.711, de 29 de agosto de 2012. Disponível em http://www.planaltogovbr/ccivil_03/_Ato2011-2014/2012/Lei/L12711htm. Acessado em 8/4/2013.

PROUNI (Programa Universidade para Todos). (2014), Dados e Estatísticas. Ministério da Educação. Disponível em http://prouniportal.mec.gov.br/index.php?option= com_content\&view=category\&id=26\&Itemid=147. Acessado em 15/4/2014.

RALWS, John. (1971), A Theory of Distributive Justice. Cambridge, The Belknap Press of Harvard University Press.

RIBEIRO, Carlos Antonio Costa. (2011), “Desigualdade de Oportunidades e Resultados Educacionais no Brasil". DADOS-Revista de Ciências Sociais, vol. 54, no 1, pp. 41-87.

ROEMER, John. (1996), Theories of Distributive Justice. Cambridge, Harvard University Press.

. (2000), "Equality of Opportunity", in K. Arrow; S. Bowles; S. Durlauf (orgs.), Meritocracy and Economic Inequality. Princeton, Princeton University Press, pp. 17-32.

. (2012), "On Several Approaches to Equality of Opportunity". Economics and Philosophy, vol. 28, oㅡ 2, pp. 165-200.

SARAIVA, Luiz Alex Silva; NUNES, Adriana de Souza. (2011), "A Efetividade de Programas Sociais de Acesso à Educação Superior: O Caso do ProUni". Revista de Administração Pública, vol. 45, no 4, pp. 941-964.

SEN, Amartya. (2009), The Idea of Justice. Cambridge, MA, Harvard University Press.

SISFIES (Sistema Informatizado do FIES). (2014), "Perguntas Frequentes". Disponível em http:/ / sisfiesportal.mec.gov.br/faq.html. Acessado em 10/2/2014. 
Cristina B. de Souza Rossetto e Flávio de Oliveira Gonçalves

TCU (Tribunal de Contas da União). (2009), Relatório da Auditoria Operacional no Programa Universidade para Todos (ProUni) e no Fundo de Financiamento ao Estudante do Ensino Superior (FIES) - Sumário Executivo. Relator Ministro José Jorge, Brasília.

TOBIN, James. (1970), “On Limiting the Domain of Inequality". Journal of Law and Economics, vol. 13, no 2, pp. 263-277.

UNDP (United Nations Development Programme). (2014), Mean Years of Schooling of Adults. Disponível em https://data.undp.org/dataset/Mean-years-of-schoolingof-adults-years-/m67k-vi5c. Acessado em 1/4/2014. 


\section{RESUMO}

Equidade na Educação Superior no Brasil: Uma Análise Multinomial das Políticas Públicas de Acesso

O presente artigo avalia, sob a base do conceito de igualdade de oportunidades, a coerência das políticas de cotas ProUni e FIES como geradoras de equidade no acesso ao ensino superior. Essas políticas têm em comum o fato de destinarem-se a parcelas específicas do alunado. Na rede privada, onde estão $75 \%$ do alunado, $18 \%$ acessam as políticas públicas de incentivo ao ingresso. A rede pública oferece vagas gratuitas e cerca de $10 \%$ dos alunos são cotistas. Segundo o critério de igualdade de oportunidades, a política deve compensar os indivíduos por limitações que estão fora do seu controle. Estatísticas descritivas e um modelo logit multinomial, utilizando microdados do Enade de 2008 a 2010, evidenciam que o sistema de acesso não oferece os mesmos benefícios para pessoas com condições de competição semelhantes. Destarte, a incoerência de incentivos da política pública desfavorece principalmente alunos da rede privada. Assim sendo, o artigo apresenta, finalmente, uma discussão de possibilidades de reforma.

Palavras-chave: educação superior; igualdade de oportunidades; FIES; ProUni; cotas

\section{ABSTRACT \\ Equity in Higher Education in Brazil: A Multinomial Analysis of the Access to Entry Public Policies}

This article evaluates the coherency of quota politics, ProUni and FIES as drivers of equity in access to higher learning, taking the concept of equality of opportunity as a premise. These policies have in common the fact that they are targeted at specific parcels of the total number of students. In the private education system, which encompasses $75 \%$ of all students, $18 \%$ have access to public policies that promote entry. The public system offers free education and approximately $10 \%$ of all students benefited from quotas. According to the criterion of equality of opportunity, policies must compensate people for limitations that are beyond their own capabilities. Descriptive statistics and a multinomial logit model using microdata from the 2008 and 2010 Enade survey provide evidence that the system of access does not offer the same benefits to people in equal standing. Thus, the incoherence of the incentives offered by public policy is unfavorable for private system students. The article concludes with a discussion of possible reforms.

Keywords: higher education; equality of opportunities; FIES; ProUni; quotas 


\section{RÉSUMÉ}

Equité dans l'Enseignement Supérieur Brésilien: Une Analyse

Multinomiale de l'Accès aux Politiques Publiques d'Entrée à l'Université

Le présent article évalue, en se basant sur le principe de l'égalité des chances, la cohérence des politiques de quotas ProUni et FIES en tant que créateurs d'équité dans l'accès à l'enseignement supérieur. Ces politiques ont en commun le fait d'être destinées à des catégories spécifiques d'étudiants. Dans le réseau privé, où se trouvent $75 \%$ des étudiants, $18 \%$ des inscrits ont eu accès aux politiques publiques d'entrée à l'université. Le réseau universitaire public est quant à lui gratuit, et près de $10 \%$ des élèves bénéficient du système de quotas. Selon le critère de l'égalité des chances, la politique doit compenser les limitations imposées aux étudiants pour des motifs échappant à leur contrôle. Des statistiques descriptives et un modèle logit multinomial utilisant des microdonnées de l'Enade de 2008 à 2010 ont mis en évidence que le système d'accès n'offre pas les mêmes avantages à des personnes dont les conditions de sélection sont pourtant similaires. On constate en outre que l'incohérence des politiques publiques nuit principalement aux étudiants du réseau privé. Pour finir, cet article proposera un débat sur les possibilités de réforme.

Mots-clés: enseignement supérieur; égalité des chances; FIES; ProUni; quotas

\section{RESUMEN}

Equidad en la Educación Superior en Brasil: Un Análisis Multinomial de las Políticas Públicas de Ingreso

El presente artículo evalúa, bajo el concepto de igualdad de oportunidades, la coherencia de las políticas de cuotas ProUni e FIES como generadoras de equidad en el acceso a la enseñanza superior. Estas políticas tienen en común el hecho de dirigirse a parcelas específicas del alumnado. En la red privada, que corresponde al $75 \%$ de los estudiantes, $18 \%$ tienen acceso a las políticas públicas de incentivo al ingreso. La red pública ofrece plazas gratuitas y cuentan con un $10 \%$ de los alumnos beneficiados por las políticas de cuotas. Según el criterio de igualdad de oportunidades, la política debe compensar los individuos por limitaciones que están fuera de su control. Tras aplicar estadísticas descriptivas y un modelo logit multinomial, utilizando micro-datos del Enade de 2008 a 2010, el artículo evidencia que el sistema de acceso no ofrece los mismos beneficios para personas con condiciones similares de competición. De este modo, la incoherencia de incentivos de la política pública desfavorece principalmente a los estudiantes de la red privada. Tras discutir estos hallazgos, se presenta, finalmente, una discusión de posibilidades de reforma.

Palabras clave: educación superior; igualdad de oportunidades; FIES; ProUni; cuotas 